\title{
Burden and Determinants of Hypertension in Rural Pondicherry, India
}

\section{Banushree C Srinivasamurthy*}

Indira Gandhi Medical College, Puducherry, India

\section{Introduction}

We found it interesting to read the article. Hypertension is an important public health challenge worldwide. Estimation of hypertension prevalence in various region helps in implementing health policies to reduce the burden of the disease. An attempt has been made to know the burden and determinants of hypertension in rural population. Population based knowledge about the magnitude and a determinant of hypertension in rural areas is scarce. Present study shows high prevalence of hypertension [24.7\%] as compared to study done in Vietnam rural population [14.1\%] [1] and less the overall global population prevalence[ 26.4\%] [2].Although demographic changes in populations will have the greatest short-term consequences for changes in population blood pressure distributions and hypertension prevalence, other factors are likely to augment these changes. In particular, progress in economic development, with consequent increases in obesity because of greater food availability and choice, and a reduction in physical activity can be expected to further increase mean blood pressure levels and the proportion with high blood pressure in lower income regions such as China and India in concurrence with present study [3]. However, the present study can be strengthened by genetic study as genetic elements contribute to $30 \%$ to $50 \%$ of the blood pressure variability [4].

\section{Conclusion}

The importance of high blood pressure as a major cause of common serious diseases should be recognized and effective preventive programs should be implemented in resource poor regions.

\section{References}

1. Van Minh H, Byass P, Chuc NTK, Wall S (2006) Gender differences in prevalence and socioeconomic determinants of hypertension: Findings from the WHO STEPs survey in a rural community of Vietnam. Journal of human hypertension 20: 109-115.

2. Kearney PM, Whelton M, Reynolds K, Muntner P, Whelton PK, et al. (2005) Global burden of hypertension: Analysis of worldwide data. The Lancet 365: 217-223.

3. Perkovic V, Huxley R, Wu Y, Prabhakaran D, MacMahon S (2007) The burden of blood pressure-related disease a neglected priority for global health. Hypertension 50: 991-997.

4. Saavedra JM (2009) Opportunities and limitations of genetic analysis of hypertensive rat strains. Journal of hypertension 27: 1129-1133.

\footnotetext{
*Corresponding author: Dr. Banushree C Srinivasamurthy, Assistant Professor, Indira Gandhi Medical College, Puducherry, India, E-mail: drbanushree15@hotmail.com

Received August 11, 2015; Accepted September 11, 2015; Published September 17, 2015

Citation: Srinivasamurthy BC (2015) Burden and Determinants of Hypertension in Rural Pondicherry, India. J Clin Med Genom 3: 127. doi: 10.4172/2472128X.1000127

Copyright: (ㅇ 2015 Srinivasamurthy BC. This is an open-access article distributed under the terms of the Creative Commons Attribution License, which permits unrestricted use, distribution, and reproduction in any medium, provided the original author and source are credited.
} 